\title{
SISTEM PERINGATAN DINI BAHAYA BANJIR KOTA SAMARINDA MENGUNAKAN SENSOR ULTRASONIC BERBASIS MIKROKONTROLER DENGAN BUZZER DAN SMS
}

\author{
Indah Fitri Astuti ${ }^{1)}$, Arton Nuary Manoppo ${ }^{2)}$, Zainal Arifin ${ }^{3)}$ \\ ${ }^{1,2,3}$ Ilmu Komputer, Fakultas Ilmu Komputer dan Teknologi Informasi, Universitas Mulawarman \\ Jalan Penajam, Kampus Gunung Kelua, Samarinda, 75242 \\ E-mail : indahfitriastuti@gmail.com ${ }^{1)}$, arton.nuari@gmail.com ${ }^{2)}$, smartza77@gmail.com ${ }^{3)}$
}

\begin{abstract}
ABSTRAK
Indonesia adalah negara yang memiliki curah hujan tinggi karena memiliki iklim tropis basah, banjir merupakan bencana alam yang sering terjadi di beberapa daerah di Indonesia salah satunya adalah di ibukota Kalimantan Timur yaitu kota Samarinda, banjir terjadi akibat tingginya curah hujan membuat sungai-sungai di kota Samarinda meluap dan dapat mengakibatkan banyak kerugian seperti bangunan, uang dan harta benda. Penelitian ini bertujuan untuk mambangun suatu untuk mengetahui kemungkinan datangnya banjir sebelum banjir terjadi menggunakan peringatan berupa pesan teks pendek. Sistem pendeteksi banjir peringatan dini ini dibangun dengan menggunakan Arduino sebagai mikrokontroler yang mengendalikan sensor ultrasonik dan sensor pendeteksi air dalam mendeteksi air (kemungkinan banjir) serta ketinggiannya. Pesan pendek akan dikirim oleh sistem dan SMS gateway yang tergantung dari tangkapan sensor air dan ketinggian air. Hasil dari penelitian ini adalah terbangunnya sebuah sistem pendeteksi peringatan dini banjir Kota Samarinda mengunakan sensor ultrasonik berbasis mikrokontroler dengan buzzer dan sms. ini diharapkan mampu memudahkan pengguna untuk mengetahui keadaan luapan air melalui tiga jenis pesan pendek yaitu status aman, siaga, dan bahaya. Setiap ketinggian air berubah maka sistem merespon dengan mengirim pesan yang sesuai.
\end{abstract}

Kata Kunci: Arduino, Banjir, Sistem, Peringatan Dini, SMS Gateway

\section{PENDAHULUAN}

Indonesia adalah negara kepulauan yang memiliki lokasi geografis pada titik koordinat $95^{\circ}$ derajat Bujur Timur sampai $141^{\circ}$ derajat Bujur Timur, serta antara $6^{\circ}$ derajat Lintang Utara sampai dengan $11^{\circ}$ derajat Lintang Selatan. Indonesia dianugerahi iklim tropis basah dengan curah hujan tinggi yang disebabkan Indonesia termasuk negara kepulauan yang sebagian daratannya dikelilingi oleh samudera.

Kota Samarinda melalui Badan Meteorologi, Klimatologi, dan Geofisika (BMKG) mencatat curah hujan di Kota Samarinda dari tahun 2000 sampai dengan tahun 2010 rata-rata mencapai $2265,23 \mathrm{~mm}$ per tahun atau 226,523 mm per bulan. BMKG mencatat ketinggian air banjir di sekitar Bandara Temindung mencapai 2,4 meter. Tingginya curah hujan menjadi salah satu penyebab utama banjir Samarinda.

Fenomena banjir yang melanda Samarinda selalu terjadi setiap tahun. Banjir terjadi akibat tingginya curah hujan sehingga sungai-sungai yang menjadi tempat penampungan utama air Samarinda meluap karena volume air melebihi kapasitas badan sungai. Banjir memiliki banyak dampak buruk yang merugikan bagi masyarakat tidak hanya kerugian secara material seperti uang, bangunan dan harta benda lainnya, banjir juga dapat menimbulkan korban jiwa. Dampak banjir dapat dikurangi jika masyarakat lebih siap dalam menghadapi datangnya banjir tersebut. Salah satu caranya adalah dengan menyebarkan informasi level ketinggian air sungai secara cepat ke masyarakat.

Berdasarkan uraian permasalahan tersebut maka dibutuhkan sistem peringatan dini bahaya banjir untuk masyarakat Samarinda. Pengukuran tingkat ketinggian air dapat dilakukan dengan mengunakan sensor ultrasonik berbasis mikrokontroler. Mikrokontroler adalah suatu Central Processing Unit (CPU) yang terdiri dari tiga bagian yaitu unit pengendali, unit aritmatika, dan unit logika. Unit pengendali untuk mengatur urutan operasi seluruh sistem pada saat pengambilan pengkodean dan melaksanakan intruksi seluruh program yang tersimpan pada suatu memori.

Sistem ini juga dilengkapi dengan modem dan modul GSM lampu led, buzzer sebagai sirine, dan informasi data analog berupa Short Message Servise (SMS) gateway sebagai output. Lampu led akan berfungsi sebagai tanda dari tingkat bahaya dari suatu ketinggian air, buzzer atau sirine yang akan berbunyi pada batas ketinggian maksimal level air yang sudah ditentukan oleh sistem dari mikrokontroler, dan SMS akan dikirimkan kepada semua nomor GSM yang didaftakan ke dalam modul GSM pesan akan disampaikan secara detail hasil pantauan realtime 24 jam. 


\section{RUANG LINGKUP PENELITIAN}

Dalam penelitian ini permasalahan mencakup:

1. Cakupan permasalahan

Berdasarkan latar belakang yang telah dikemukakan, maka dirumuskan suatu permasalahan yaitu bagaimana membangun suatu alat peringatan dini bahaya banjir dengan sensor ultrasonik berbasis mikrokontroler Arduino Uno.

2. Batasan-batasan penelitian

Penelitian perlu dibatasi agar pembahasannya tidak meluas. Penelitian ini dibatasi pada:

1) Sensor yang digunakan dalam penelitian ini adalah sensor ultrasonik.

2) Sistem yang bertugas untuk mengatur seluruh kegiatan sistem yang dirakit dirancang berbasis mikrokontroler ATMEGA328.

3) Tingkat ketinggian air (potensi banjir) akan ditandai dengan lampu $L E D$ dan bunyi buzzer sebagai sistem peringatan dini.

4) Sistem ini sifatnya berupa caution atau peringatan awal/dini kepada masyarakat

5) Tidak memuat komputasi secara fisika.

3. Rencana hasil yang didapatkan dari penelitian ini adalah suatu yang mampu mendeteksi tingkat ketinggian air dengan menggunakan sensor berbasis ultrasonik.

\section{BAHAN DAN METODE}

\subsection{Mikrokontroller}

Mikrokontroler merupakan suatu chip IC (Integrated Circuit) yang dapat menerima sinyal input, mengolahnya dan memberikan sinyal output sesuai dengan program dimasukan. Terdapat CPU, memori, jalur Input/Output (I/O) dan perangkat pelengkap lainnya. Kecepatan pengolahan data pada mikrokontroler lebih rendah jika dibandingkan dengan $P C$. Kecepatan mikroprosesor yang digunakan pada sebuah $P C$ saat ini telah mencapai orde $\mathrm{GHz}$, sedangkan kecepatan operasi mikrokontroler pada umumnya berkisar antara 1-16 MHz. Kapasitas $R A M$ dan $R O M$ pada $P C$ yang bisa mencapai orde Gbyte, dibandingkan dengan mikrokontroler yang hanya berkisar pada orde byte/Kbyte (Wibawa et al, 2013).

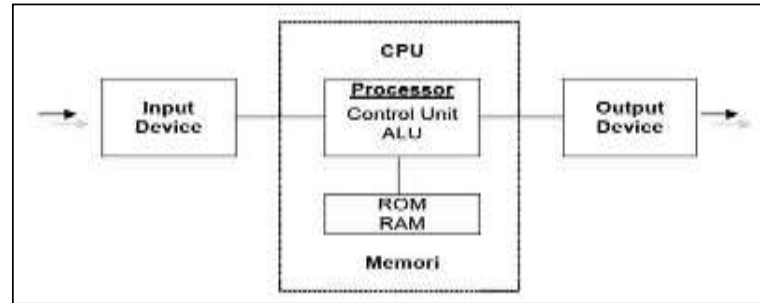

Gambar 1. Komponen Mikrokontroller

\subsection{Arduino}

Program board Arduino, dibutuhkan aplikasi IDE dari (Integrated Developtment Enviroenment). Melalui software inilah Arduino dilakukan pemrograman untuk melakukan fungsi-fungsi melalui sintaks pemrograman. Arduino menggunakan bahasa pemrograman sendiri yang menyerupai Bahasa C. Bahasa pemrograman
Arduino (Sketch) sudah dilakukan perubahan untuk memudahkan pemula dalam melakukan pemrograman dari bahasa aslinya. IC mikrokontroler Arduino telah ditanamkan suatu program bernama Bootlader yang berfungsi sebagai penengah antara compiler Arduino dengan mikrokontroler. Arduino IDE dibuat dari bahasa pemrograman JAVA. Arduino IDE juga dilengkapi dengan library $\mathrm{C} / \mathrm{C}++$ yang biasa disebut Wiring yang membuat operasi input dan output menjadi lebih mudah. Arduino IDE ini dikembangkan dari software processing yang dirombak menjadi Arduino IDE khusus untuk pemrograman dengan Arduino (Santoso, 2015).

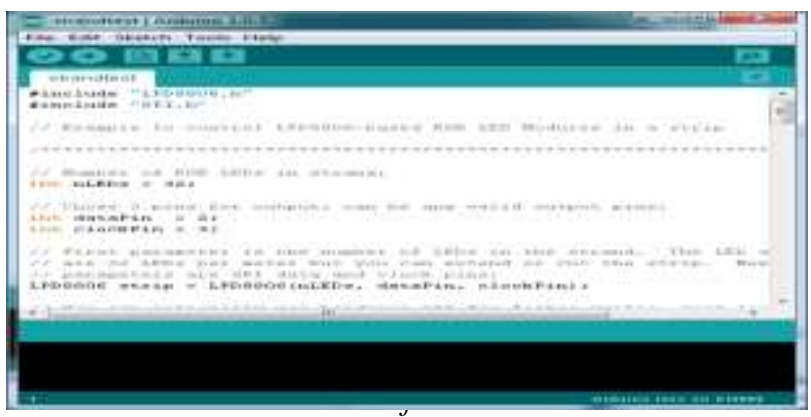

Gambar 2. Tampilan Arduino IDE

Tampilan Arduino IDE tampak seperti gambar 2. Bagian-bagian IDE Arduino terdiri dari: (Santoso, 2015)

1. Verify, pada versi sebelumnya dikenal dengan istilah compile. Sebelum aplikasi diunggah ke board Arduino, dapat memverifikasi terlebih dahulu sketch yang dibuat. Jika ada kesalahan pada sketch, nanti akan muncul error. Proses verify/compile mengubah sketch ke binary code untuk diunggah ke mikrokontroller.

2. unggah, tombol ini berfungsi untuk mengunggah sketch ke board Arduino. Walaupun tidak mengklik tombol verify, maka sketch akan dicompile, kemudian langsung diunggah ke board. Berbeda dengan tombol verify yang hanya berfungsi untuk memverifikasi source code saja.

3. New sketch, untuk membuka window dan membuat sketch baru.

4. Open sketch, untuk membuka sketch yang sudah pernah dibuat. Sketch yang dibuat dengan IDE Arduino akan disimpan dengan ekstensi file.ino

5. Save sketch, untuk menyimpan sketch, tapi tidak disertai meng-compile.

6. Serial monitor, untuk membuka interface untuk komunikasi serial.

7. Keterangan aplikasi, pesan-pesan yang dilakukan aplikasi akan muncul disini, misal "Compiling" dan "Done Uploading" ketika meng-compile dan mengunggah sketch ke board Arduino.

8. Konsol, pesan-pesan yang dikerjakan aplikasi dan pesan-pesan tentang sketch akan muncul pada bagian ini. Misal, ketika aplikasi meng-compile atau ketika ada kesalahan pada sketch yang dibuat, maka informasi error dan baris akan diinformasikan di bagian ini. 
9. Baris sketch, bagian ini akan menunjukkan posisi baris kursor yang sedang aktif pada sketch.

\subsection{Arduino Uno}

Papan Arduino Uno merupakan papan mikrokontroler yang berukuran kecil atau dapat digambarkan sebagai suatu rangkaian berukuran kecil yang didalamnya terdapat komputer berbentuk suatu chip. Gambar 3 menunjukkan sebuah papan Arduino dengan beberapa bagian komponennya (Rohman, 2015).

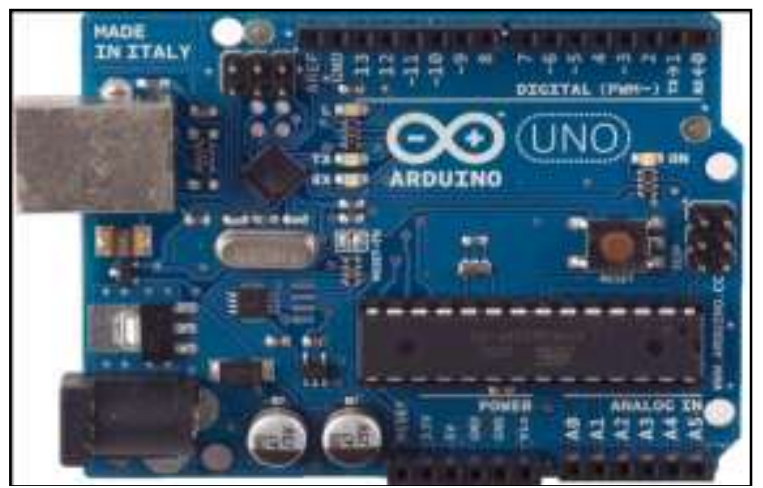

Gambar 3. Papan Arduino Uno

Arduino menggunakan bahasa $\mathrm{C}$ walaupun banyak sekali terdapat bahasa pemrograman tingkat tinggi (high level language) seperti Pascal, Basic, Cobol, dan lainnya. Walaupun demikian, sebagian besar dari para programmer profesional masih tetap memilih bahasa $\mathrm{C}$ sebagai bahasa yang lebih unggul, karena:

1) Bahasa $\mathrm{C}$ merupakan bahasa yang dan fleksibel yang telah terbukti dapat menyelesaikan program-program besar seperti pembuatan sistem operasi, pengolah gambar (seperti pembuatan game) dan juga pembuatan kompilator bahasa pemrograman baru.

2) Bahasa $\mathrm{C}$ merupakan bahasa yang portable sehingga dapat dijalankan di beberapa sistem operasi yang berbeda. Sebagai contoh program yang ditulis dalam sistem operasi windows dapat dikompilasi didalam sistem operasi LINUX dengan sedikit ataupun tanpa perubahan sama sekali.

3) Bahasa $\mathrm{C}$ merupakan bahasa yang sangat populer dan banyak digunakan oleh programmer berpengalaman sehingga kemungkinan besar library pemrograman telah banyak disediakan oleh pihak luar dan dapat diperoleh dengan mudah.

4) Bahasa $\mathrm{C}$ merupakan bahasa yang bersifat modular, yaitu tersusun atas rutin-rutin tertentu yang dinamakan dengan fungsi(function) dan fungsifungsi tersebut dapat digunakan kembali untuk pembuatan program-program lainnya tanpa harus menulis ulang implementasinya.

5) Bahasa C merupakan bahasa tingkat menengah (middle level language) sehingga mudah untuk melakukan interface (pembuatan program antar muka) ke perangkat keras.

Struktur penulisan program dalam bahasa $\mathrm{C}$ harus memiliki fungsi utama, yang bernama main (). Fungsi inilah yang akan dipanggil pertama kali pada saat proses eksekusi program. Apabila mempunyai fungsi lain selain fungsi utama, maka fungsi lain tersebut baru akan dipanggil pada saat digunakan.

Bahasa C merupakan bahasa prosedural yang menerapakan konsep runtutan (program dieksekusi per baris dari atas ke bawah secara berurutan) (Setiawan, 2011).

\section{RANCANGAN SISTEM}

Perancangan program sistem peringatan dini banjir ini terdiri dari beberapa tahap. Pembuatan Flowchart selanjutnya Souce Code dibuat menggunakan Arduino IDE yang merupakan program yang akan menjalankan perintah-perintah pada alat ini, kemudian semua perintah Upload ke-Mikrokontroler dengan menggunakan media kabel USB.

\subsection{Perancangan Alat}

Pembuatan sistem peringatan banjir ini melalui beberapa tahap pembuatan. Langkah pertama adalah mempersiapkan alat dan bahan yang akan digunakan, seperti penyusunan mainboard arduino. Langkah kedua adalah meletakkan komponen-komponen eletronika agar dapat memudahkan dan penyesuaian sistem dalam penggunaannya. Proses berikutnya adalah membuat rangkaian skematik elektronik sistem peringatan dini banjir dimana pada mikrokontroler Arduino ATMega328 dihubungkan ke beberapa komponen lainnya seperti Sensor Ultrasonik HC-SR04, Sim8001, buzzer, indikator LED, LCD 16x2, Baterai, dan beberapa komponen yang lain.

\subsection{Pembuatan Rangkaian}

Tahap pembuatan rangkaian ini adalah dengan mempersiapkan komponen yang akan digunakan seperti, Sensor UltraSonik HC-SR04, Arduino Uno ATMega328. Arduino Uno memiliki Mikrokontroler ATMega328 didalamnya yang memiliki 13 pin input/output digital (6 Output untuk PWM). Rangkaian Arduino juga telah dilengkapi dengan IC regulator yang berfungsi sebagai rangkaian Power Supply. Rangkaian ini ditambahkan dengan adanya Buzzer sebagai alarm, LCD 16x2 sebagai tampilan nilai ketinggian air dan LED yang berfungsi sebagai salah satu bentuk notifikasi berupa kedipan lampu pada rangkaian mendapatkan inputan listrik 5 Volt untuk memberikan masukan ke Arduino.

\subsection{Flowchart}

Gambar 4 merupakan flowchart sistem atau bagan alir sistem dimana sistem pertama kali dijalankan, sistem akan melakukan proses inisialisasi perangkat input/output yang digunakan untuk menghubungkan dengan perangkat luar seperti sensor, LCD, Buzzer, LED, dansim8001.

Mikrokontroler akan melakukan proses pembacaan sensor ultrasonik, jika terdeteksi ketinggian air maka yang pertama dilakukan adalah menampilkan nilai level ketinggian pada LCD 16x2 cm, selanjutnya dilakukan pengiriman sms ke nomor tujuan yang sudah tersimpan di dalam program sim8001. SMS hanya akan dikirim 1 kali setiap adanya perubahan level ketinggian air. 


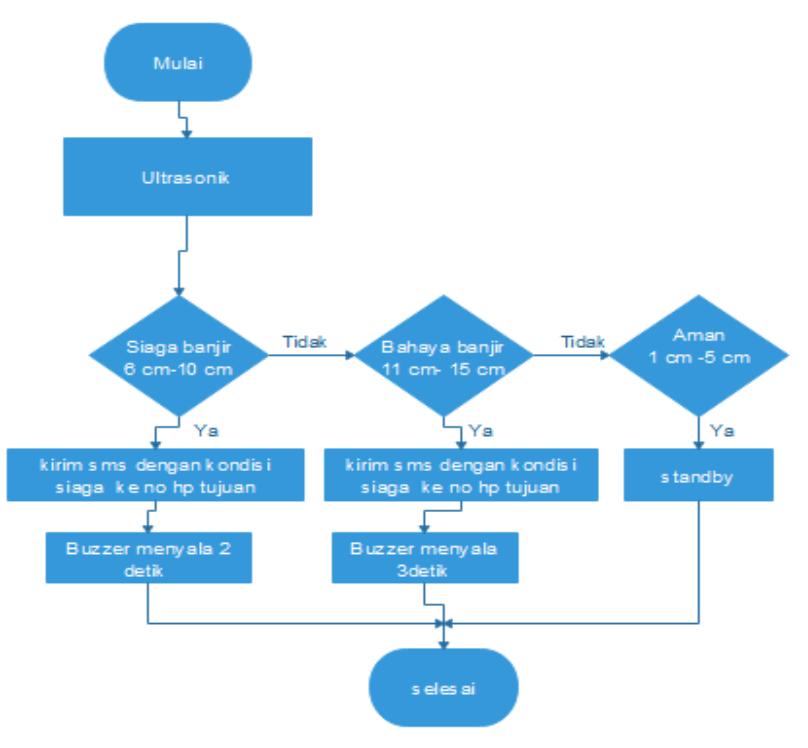

Gambar 4. Flowchart Sistem Peringatan Dini Banjir

\section{IMPLEMENTASI}

Purwarupa sistem peringatan dini bahaya banjir ini mengunakan sensor ultrasonik berbasis mikrokontroler dengan buzzer dan sms yang merupakan rancangan alat untuk mendeteksi jarak antara benda yang berada di depannya dengan menggunakan gelombang di frekuensi $40 \mathrm{kHz}$ dengan rentang deteksi dari $4-300 \mathrm{~cm}$, dengan gelombang suara $40 \mathrm{kHz}$ maka sensor ini dapat mendeteksi atau memantukan kembali gelombang suara yang terkena permukaan air atau benda padat.

Penggunaan alat ini akan berjalan otomatis berdasarkan perintah-perintah atau source code yang ditanamkan ke dalam mikrokontroler tersebut. Sensor ultrasonik yang dipasang pada alat dan dengan penempatan dimana sensor ini ditempatkan tepat di baskom yang diisi air dengan jarak yang sudah ditentukan sesuaikan dengan kebutuhan, dan memberikan pemberitahuan melalui SMS.

Sensor ultrasoik akan dipasang tepat di atas wadah yang akan diisi air dengan jarak yang disesuaikan dengan kebutuhan. Sensor akan mendeteksi ketinggian air yang melewati level level ketinggian air yang sudah ditentukan dan memberikan SMS berisikan informasi sesuai ketinggian level air. level ketinggian air dibedakan menjadi 3 bagian yaitu:

1. level aman ketinggian air antara $1-5 \mathrm{~cm}$.

2. level siaga ketinggian air antara $6-10 \mathrm{~cm}$.

3. Level bahaya ketinggian air antara $11 \mathrm{~cm}$ dan seterusnya.

Sistem ini memliki 4 komponen output yaitu LCD, Lampu Led, Buzzer dan Sms. Purwarupa ini menghasilkan sebuah peringatan melalui SMS, dengan menggunakan sebuah hardware sim8001 yang langsung terpasang pada board Arduino. Sms akan otomatis terkirim jika ketinggian air telah menyentuh titik level ketinggian air yang sudah ditentukan yaitu titik aman, titik siaga, dan bahaya. Pesan sms akan berubah jika sensor ultrsonik mendeteksi ketinggian air berubah dari titik 0 dan terus meningkat hingga di titik $5 \mathrm{~cm}, 10 \mathrm{~cm}, 15$ $\mathrm{cm}$. Gambar 5 menunjukkan sistem dengan level air 'aman', sedangkan gambar 6 dengan level 'bahaya'.

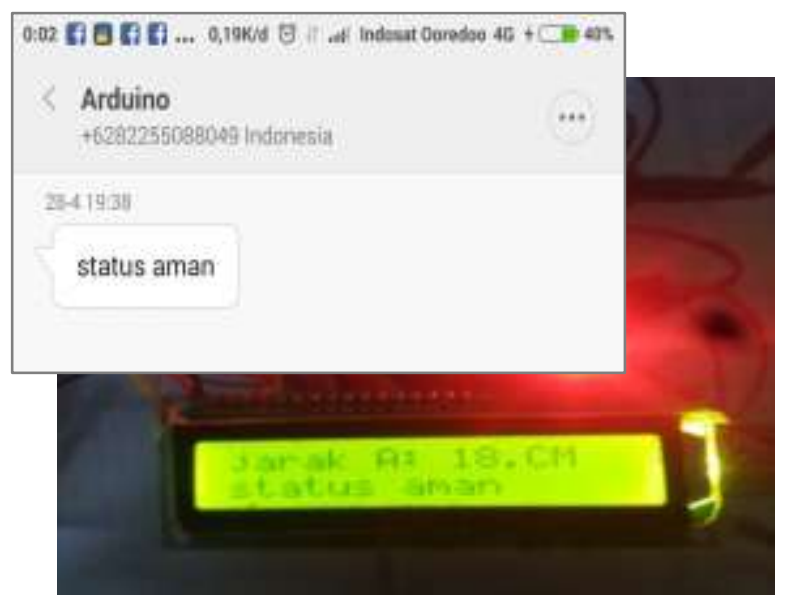

Gambar 5. Hasil Kerja dengan Status 'aman'

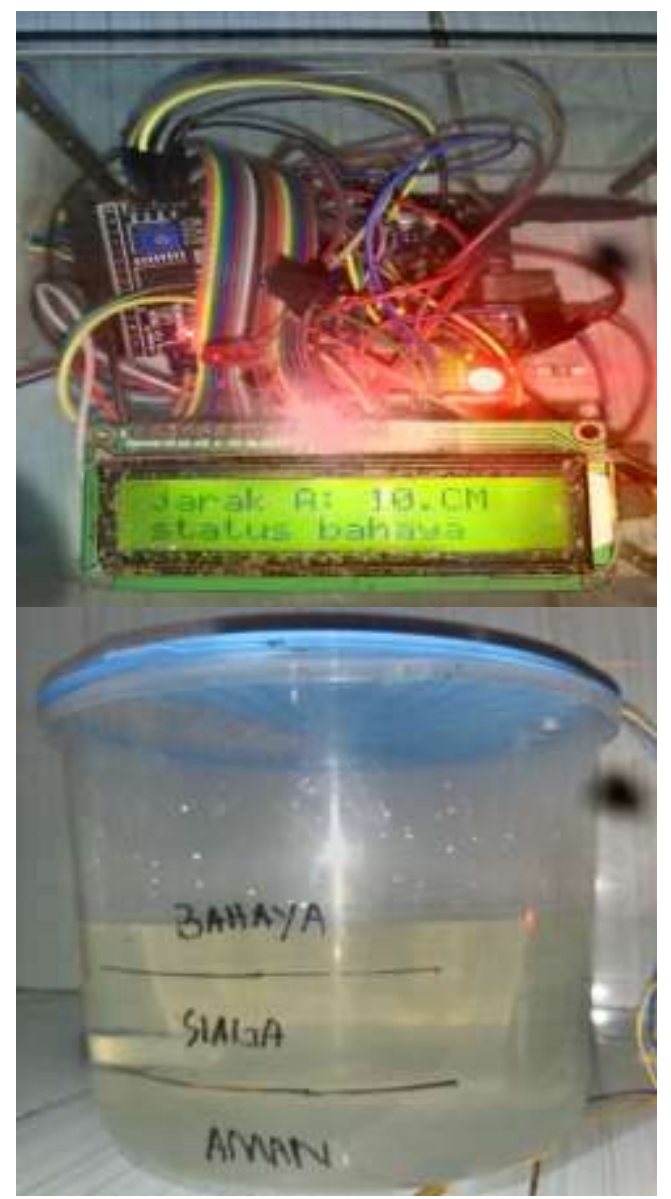

Gambar 6. Hasil Kerja dengan Status 'Bahaya' 


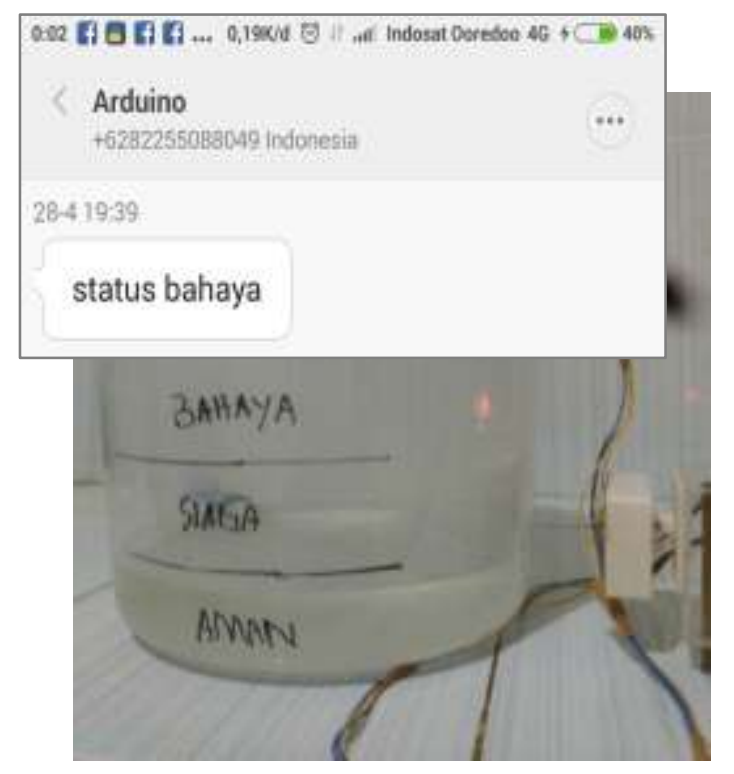

Gambar 7. SMS Status 'Bahaya'

\section{KESIMPULAN}

Berdasarkan rangkaian kerja penelitian ini dapat diambil kesimpulan antara lain:

1. Alat sistem peringatan dini banjir ini dapat bekerja dengan baik, dikarenakan semua komponen penting seperti Sensor Ultrasonik, LCD, LED Buzzer dan Sim8001 dapat berjalan dengan baik.

2. Sensor ultrasonik HC-SR04 memiliki rentang deteksi hingga $4-300 \mathrm{~cm}$ sensor ini memiliki titik buta jika jarak air sudah sangat dekat dengan sensor jarak titik buta sensor adalah $1-3 \mathrm{~cm}$.

\section{SARAN}

Terdapat beberapa saran yang sangat berguna untuk tahap pengembangan selanjutnya, yaitu:

1. Memberikan tambahan perangkat Ethernet shield agar sistem dapat terhubung dengan internet.

2. Sensor ultrasonik yang digunakan oleh sistem peringantan dini banjir untuk mengukur ketinggian air secara teori sangat baik, tapi memiliki kelemahan karena frekuensi yang dikeluarkan oleh sensor dapat memantul apabila terkena permukaan padat lain seperti metal, kayu, dan benda padat lain.

\section{DAFTAR PUSTAKA}

Rohman, A, Z, 2015, Rancang Bangun Alat Ukur Getaran Mesin Berbasis Arduino, Jurusan Teknik Elektro, Universitas Negeri Semarang.

Santoso, H, 2015, Panduan Praktis Arduino untuk Pemula. Diakses pada tanggal 12 April 2017 dari www.elangsakti.com

Setiawan, A, 2011, Aplikasi Mikrokontroller ATMega 8535 dan ATMega Menggunakan BASCOM-AVR, Yogyakarta: Andi Offset.

Wibawa, A.H, Saputra, R, Satria, R, 2013, Sistem Peringatan Dini Meluapnya Air Sungai Menggunakan SMS Gateway dan Mikrokontroller. Semarang: Universitas Diponegoro

Yudhana, A., \& Pratama, U. S. 2017. Otomatisasi Sistem Penyiraman dan Pemupukan Tanaman Berbasis Mikrokontroler ATMEGA8535. Prosiding SN Sebatik, 1(1), 96-100. 